\section{A mutated factor $X$ activatable by thrombin corrects bleedings in vivo in a rabbit model of antibody-induced hemophilia A}

\author{
Toufik Abache, ${ }^{1}$ Alexandre Fontayne, ${ }^{1}$ Dominique Grenier, ${ }^{1}$ Emilie Jacque,${ }^{1}$ \\ Alain Longue, ${ }^{1}$ Anne-Sophie Dezetter, ${ }^{1}$ Béatrice Souilliart, ${ }^{2}$ Guillaume \\ Chevreux, ${ }^{2}$ Damien Bataille, ${ }^{2}$ Sami Chtourou ${ }^{1}$ and Jean-Luc Plantier ${ }^{1}$
}

${ }^{1}$ LFB Biotechnologies, Direction de l'Innovation Thérapeutique, Loos and ${ }^{2}$ LFB Biotechnologies, Direction Générale du Développement, Les Ulis, France

\section{ABSTRACT}

$\mathrm{R}$ endering coagulation factor $\mathrm{X}$ sensitive to thrombin was proposed as a strategy to bypass the need for factor VIII. In this study, this nonreplacement strategy was evaluated in vitro and in vivo for its ability to correct factor VIII but also factor IX, X and XI deficiencies. A novel modified factor X, named actiten, was generated and produced in the HEK293F cell line. The molecule possesses the required post-translational modifications, partially maintaining its ability to be activated by RVV-X, factor VIIa/tissue factor, and factor VIIIa/factor IXa and acquires the ability to be activated by thrombin. The potency of the molecule was evaluated in plasma samples with deficiencies of the respective factors and in plasma samples from patients with hemophilia A, some of which contained inhibitors. Actiten dose-dependently corrected all the deficient plasmas that were assayed. It was able to normalize the thrombin generation at $20 \mu \mathrm{g} / \mathrm{mL}$ although the lag time was increased. It was then assayed in a rabbit antibody-induced model of hemophilia $\mathrm{A}$ in which, in contrast to recombinant wild-type factor $\mathrm{X}$, it normalized the bleeding time and the loss of hemoglobin. No sign of thrombogenicity was observed and the generation of activated factor X was controlled by the anticoagulation pathway in all the coagulation assays performed. These data indicate that actiten may be considered as a possible non-replacement factor to treat hemophilia, with the advantage of being a zymogen that corrects bleeding only when needed.

\section{Introduction}

Hemophilia results from a default of coagulation factor IX or VIII (FIX or FVIII). It is treated by prophylactic or on-demand infusions of the missing or deficient factor. ${ }^{1}$ While offering a satisfying protection against bleeding, repeated infusions, required to maintain an active threshold of factor, are uncomfortable for patients being deleterious to the venous access, and bringing risks of infection and of developing inhibitors against the substitutive factor. ${ }^{2}$ These drawbacks justify a continuous search for improvement of hemophilia treatments, in particular prolonging the product's circulating half-life. ${ }^{3,4}$ This property is sought in order to maintain a higher threshold of coagulation, aiming to increase the treatment efficiency and compliance. ${ }^{5}$

With regards to hemophilia B, the fusion of FIX to an IgG1 Fc fragment or to albumin allowed a significant increase in FIX half-life, a less frequent administration schedule and a higher product threshold. ${ }^{5-7}$ In contrast, there was a limited improvement for hemophilia A using therapeutics based on the FVIII backbone. Persistence in the circulation of these therapeutic compounds is driven by the halflife of the FVIII chaperone, von Willebrand factor (VWF), which is only 1.5-fold greater than that of FVIII. Thus, modifications to FVIII only moderately improve a patient's exposure to the therapeutic protein. ${ }^{\text {. }}$

In recent years, a novel class of agents to treat hemophilia has emerged. These agents are based on non-replacement factors (NRF), i.e. they are independent of FVIII or FIX molecules. Some NRF diminish the level of anticoagulation, reinforcing
Ferrata Storti Foundation

Haematologica 2020

Volume 105(9):2335-2343

\section{Correspondence:}

JEAN-LUC PLANTIER

plantierj@lfb.fr

Received: February 18, 2019.

Accepted: November 5, 2019.

Pre-published: November 7, 2019.

doi:10.3324/haematol.2019.219865

(C)2020 Ferrata Storti Foundation

Material published in Haematologica is covered by copyright. All rights are reserved to the Ferrata Storti Foundation. Use of published material is allowed under the following terms and conditions:

https://creativecommons.org/licenses/by-nc/4.0/legalcode. Copies of published material are allowed for personal or internal use. Sharing published material for non-commercial purposes is subject to the following conditions:

https://creativecommons. org//icenses/by-nc/4.0/legalcode, sect. 3. Reproducing and sharing published material for commercial purposes is not allowed without permission in writing from the publisher. 
the potency of the traces of thrombin generated during the initiation of coagulation. These are a short interfering (si)RNA inhibiting the expression of antithrombin and several monoclonal antibodies targeting the tissue factor pathway inhibitor. ${ }^{9,10}$ Downmodulation of the anticoagulant system (activated protein C or protein S) also enters this category. ${ }^{11,12}$ Another NRF aims to substitute the function of FVIII. A bispecific antibody called emicizumab, which facilitates the interaction of endogenous FIX/FIXa with factor X (FX), demonstrated its potency in this setting. ${ }^{13-15}$ These NRF are pharmacological agents with a mechanism of action that is independent of the fate of FVIII or VWF, thus offering drugs with a longer half-life, for the patients' comfort, while restoring a partial but clinically sufficient coagulation.

A third, proposed NRF strategy is to redirect the activation of FX. ${ }^{16} \mathrm{FX}$ is at the crossroads of the intrinsic and extrinsic coagulation pathways and is responsible for the activation of prothrombin to thrombin. Rendering FX activatable to thrombin allows the thrombin that appears during the initiation of coagulation to generate larger amounts of FXa. These supplemental amounts will be enough to bypass the need for FVIIIa, the natural amplifier of coagulation. Such a modified FX was demonstrated in vitro to correct FVIII-deficient plasma. ${ }^{16}$ In this study, a second generation of recombinant thrombin-activatable FX (actiten) was created, in which, notably, the activation peptide was preserved in order to maintain FX pharmacokinetics in vivo. ${ }^{17}$ The ability of this molecule to correct several coagulation factor deficiencies was assessed in vitro and in a rabbit antibodyinduced model of hemophilia A.

\section{Methods}

\section{Material}

The materials used in this study are listed in the Online Supplement.

\section{Recombinant protein preparation}

The generation and production of actiten and recombinant FX constructs are explained in detail in the Online Supplement.

\section{Purification using an anti-Gla aptamer}

Re-calcified supernatant was loaded on an anti-Gla aptamer column containing the proprietary Mapt1.2CSO aptamer (Eurogentec, Liège, Belgium). The equilibration buffer was $50 \mathrm{mM}$ Tris- $\mathrm{HCl}, 10 \mathrm{mM} \mathrm{CaCl}_{2}, \mathrm{pH}$ 7.5. After a wash with the equilibration buffer $+300 \mathrm{mM} \mathrm{NaCl}$, the bound compounds were eluted with $50 \mathrm{mM}$ Tris-HCl, $10 \mathrm{mM}$ EDTA, pH 7.5. Fractions corresponding to the protein peak were pooled. Eventual traces of FXa were inhibited by $10 \mu \mathrm{M}$ GGACK and the eluate was concentrated with a $50 \mathrm{kDa}$ tangential flow filtration system then dialyzed in $\mathrm{NaCl} 0.9 \%$ and stored at $-80^{\circ} \mathrm{C}$. The absence of FXa was controlled by incubating the actiten preparation $(100 \mathrm{nM})$ with $\mathrm{FXa}$ substrate (pNAPEP 1065) for $30 \mathrm{~min}$ at $37^{\circ} \mathrm{C}$.

\section{Antigen dosage, electrophoresis and immunoblotting}

An enzyme-linked immunosorbent assay (ELISA) for FX (Zymutest Factor X, Hyphen, France) was performed according to the manufacturer's instructions.

For sodium dodecylsulfate polyacrylamide gel electrophoresis, proteins were deposited on Gel NuPAGE Novex Bis-Tris 4-12\% and migrated at 200 V. The gel was stained with PageBlue Protein
Staining Solution or transferred onto a polyvinylidene fluoride membrane and revealed by anti-Gla or anti-FX antibody.

\section{Binding to phospholipids}

FX binding was evaluated by ELISA on phospholipid dry-coated plates. Details of the protocol are provided in the Online Supplement.

\section{Activation of actiten}

All activation reactions of actiten were conducted in Hepes buffer and were stopped in EDTA-containing buffers before the amount of FXa generated was measured following the degradation of pNAPEP 1065. A standard curve of human FXa was used as the reference. The conditions for each activation are described in detail in the Online Supplement.

\section{In vitro evaluation of the thrombotic potential of actiten}

FX-deficient plasma was re-calcified to a final concentration of $7.5 \mathrm{mM}$ calcium. Plasma-derived FX (pdFX), pdFX + plasmaderived activated FX (pdFXa) or actiten was incubated at $37^{\circ} \mathrm{C}$ until clotting of the mixture. A similar experiment was conducted in FVIII-deficient plasma spiked with FVIII, pdFXa or actiten.

\section{Thrombin generation assay}

The performance of the thrombin generation assay was based on the Calibrated Automated Thrombogram method developed by Hemker et al. ${ }^{18}$ The values of the assay are the means of duplicates of two to five independent experiments. Normal plasma values were from 13 independent assays. Values for actiten (20 $\mu \mathrm{g} / \mathrm{mL}$ ) are from at least three independent experiments.

\section{In vivo evaluation of actiten}

In vivo studies were conducted in accordance with procedures approved by the Institutional Animal Care and Use Committee (CEEA26: A16_004). The rabbit model was rendered hemophiliac following infusion of anti-FVIII and the bleeding assay is described in the Online Supplement.

\section{Statistical analysis}

In vitro data are presented as means \pm standard deviation. In vivo data were analyzed using Prism 5 software (GraphPad Software Inc.) and are represented as means \pm standard error of mean. In addition, all statistical comparisons were carried out using the nonparametric two-tailed Mann-Whitney test. Statistically significant differences are indicated in the figures: ${ }^{*} P<0.05$ and ${ }^{* *} P<0.01$.

\section{Results}

\section{Expression of actiten, a thrombin-sensitive factor $X$}

A FX sensitive to thrombin was generated by inserting a 10-amino acid polypeptide between the carboxyl terminus of the activation peptide and the amino terminus of the heavy chain. The polypeptide was composed of six amino acids of fibrinopeptide $\mathrm{A}$ and four amino acids forming a thrombin cleavage site. The resulting molecule was called actiten (Figure 1). It was expressed in the HEK293F cell line and purified using a proprietary aptamer column recognizing the $\gamma$-carboxylated (Gla) domain of the coagulation factor. The molecule was immunodetected by anti-Gla monoclonal and polyclonal anti-human FX antibodies (Figure 2). In native conditions, purified actiten appeared as a unique band at 64-66 kDa. Under reducing conditions, the anti-Gla antibody revealed the FX light 
chain $(20 \mathrm{kDa})$ and a minor fraction of the molecule that was not reduced. In reducing conditions, the polyclonal anti-FX mainly revealed the heavy chain at $50 \mathrm{kDa}$ and barely the non-reduced FX fraction and the light chain. The molecular weight of actiten was $3-4 \mathrm{kDa}$ greater than that of pdFX, probably because of its additional peptide.

The molecule was analyzed by reverse phase high-performance liquid chromatography following activation with a FX activator from Russell's viper venom (RVV-X) (Online Supplementary Figure S1). This analysis demonstrated the presence of the expected post-translational modifications. The light chain contained $11 \mathrm{Gla}$, in addition to Cterminal heterogeneity, also found in pdFX. The other post-translational modifications were identical to those in pdFX. The heavy chain was found complete with a minor population under a $\beta$ form. O-glycosylation was also detected within the heavy chain. ${ }^{19}$ The activation peptide with the 10 amino-acid polypeptide added was completely liberated from the heavy chain by the RVV-X. It contained three $\bigcirc$-glycosylations. ${ }^{19}$
The presence of the expected number of Gla allowed actiten to interact efficiently with phospholipids in a solid phase assay (Figure 3). The interaction was similar albeit slightly less efficient than that of pdFX. The half-life of actiten was then evaluated in rabbits in which pdFX had been previously studied. Both products had a similar halflife (at around $6 \mathrm{~h}$ ) indicating that the modification of the FX did not affect its pharmacokinetics (Online Supplementary Figure S2). These data indicate that a mutated recombinant FX possessing an expected structure, pharmacokinetics and post-translational modifications was produced in HEK293F cells.

\section{Evaluation of actiten activation}

Actiten was activated by RVV-X, the FVIIa/tissue factor (TF) complex and the FVIIIa/FIXa complex. The percentage of activation of actiten in comparison to that of pdFX was calculated from the initial velocity of FXa generation. Actiten maintained the ability to be activated by the natural FX effectors. However, whereas activation by RVV-X

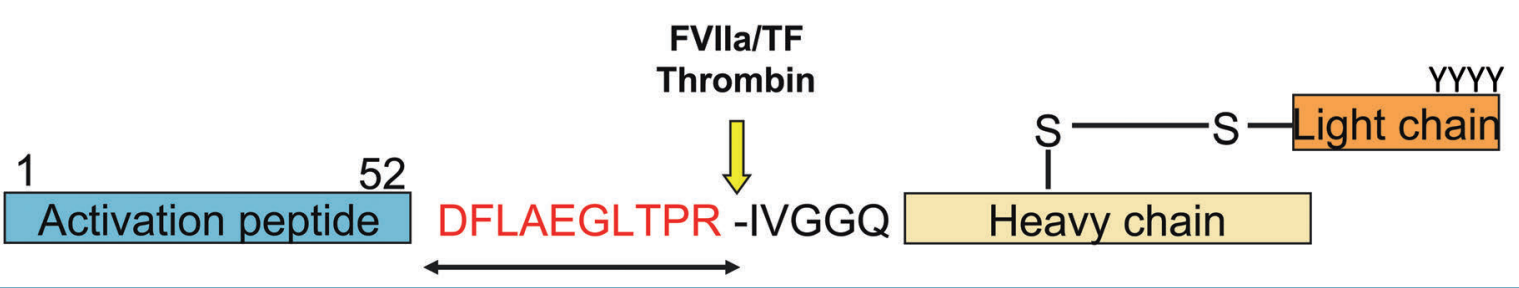

Figure 1. Schematic representation of actiten. The scheme focuses on the factor $X(F X)$ heavy chain: at the N-terminus of the heavy chain, the natural sequence of the FX activation peptide (AP) $1 \rightarrow 52$ ends at Arg234; in red a 10-amino acid peptide added between the AP and the catalytic domain (IVGGQ--) modifying the specificity of FX. The yellow arrow indicates the activation site. The light chain containing the $\gamma$-carboxylation sites is represented in orange.

A

\section{$\begin{array}{lllll}1 & 2 & 3 & 4 & 5\end{array}$}

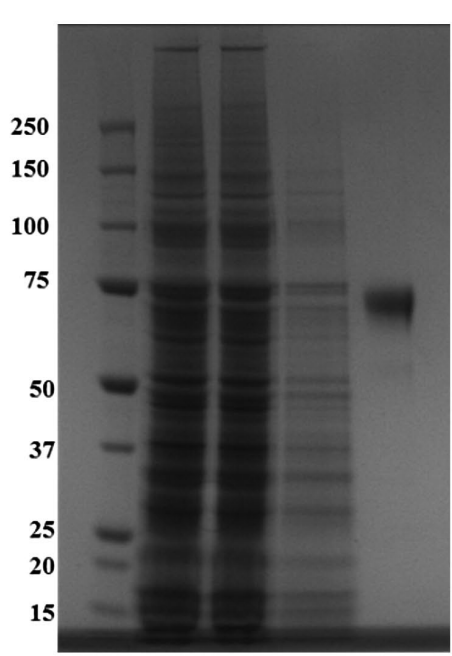

B

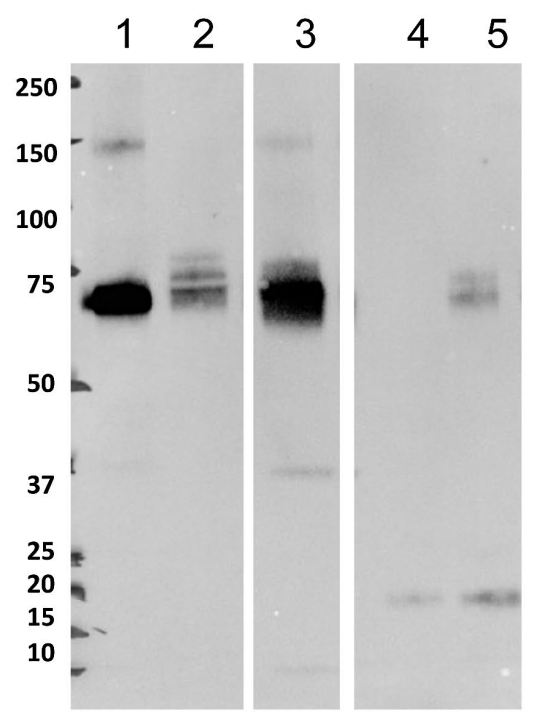

C
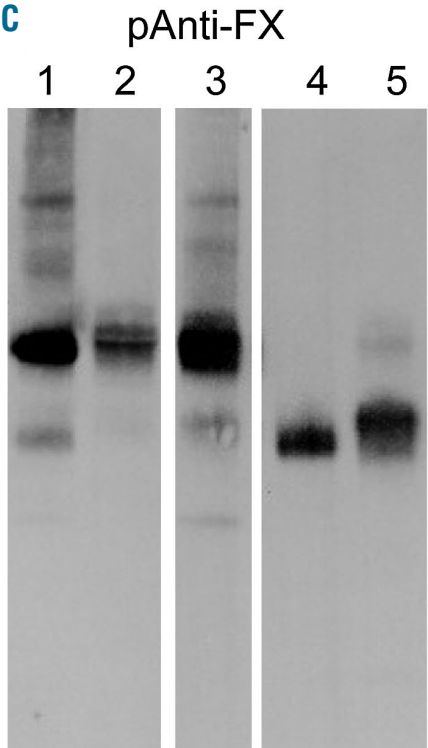

Figure 2. Visualization of purified actiten from HEK293F cells. Actiten was purified using an anti-Gla aptamer column and was separated by electrophoresis on a 4-12\% sodium dodecylsulfate polyacrylamide gel. (A) PAGE Blue staining. Lane 1, molecular weight (values in kDa are on the left of the gel); lane 2, HEK293F supernatant; lane 3, flow-through; lane 4, washes; lane 5, purified actiten. (B) Detection of Gla using a monoclonal antibody (MoAb anti-Gla). Molecular weight values in $\mathrm{kDa}$ are on the left of the gel. Lane 1, non-reduced plasma-derived FX (pdFX); lane 2, non-reduced HEK293F supernatant; lane 3, non-reduced purified actiten; lane 4, dithiothreitol (DTT)-reduced pdFX; lane 5, DTT-reduced purified actiten. (C) Detection of FX by polyclonal antibodies (pAnti-FX). Lane 1, non-reduced pdFX; lane 2, non-reduced HEK293F supernatant; lane 3, non-reduced purified actiten; lane 4, DTT-reduced pdFX; lane 5, DTT-reduced purified actiten. Separated lanes from (B) and $(C)$ are from the same gel but some bands not related to this article were removed. The signals were not adjusted. 
was moderately affected $(63 \pm 11.97 \%$ that of pdFX), activation by FVIIa/TF was impaired, being $31 \pm 1.14 \%$, and activation by the "tenase complex" was even more affected since actiten had only $20 \pm 1.23 \%$ of the capacity of pdFX.

The ability of actiten to be activated by thrombin was assessed in the absence of phospholipids (Figure 4). Phospholipids were omitted in this assay to eliminate the risk of auto-activation or degradation due to the appearance of $\mathrm{FXa}^{20,21}$ Incubation of pdFX with or without thrombin or actiten alone for $48 \mathrm{~h}$ at $37^{\circ} \mathrm{C}$ did not generate any FXa. This result confirms that our preparation of actiten did not contain traces of FXa. In contrast, the incubation of actiten with thrombin led to the appearance of a regular amount of FXa, indicating that the modification of the activation peptide rendered actiten sensitive to thrombin. The $k$ cat $/ \mathrm{Km}$ was calculated and was found to be $1.25 \pm 0.1 \times 10^{3} \mathrm{M}^{-1} \mathrm{~s}^{-1}$, a value close to the modified FX (FXfpa) generated by Louvain-Quintard et al. ${ }^{16}$

To complete this evaluation, the molecule was incubated for $6 \mathrm{~h}$ in the presence of phospholipids and FXa, at $10 \%$ of the actiten concentration. There was no supplemental generation of FXa other than the $10 \%$ added, suggesting that actiten resisted FXa cleavage (data not shown). ${ }^{21}$

The presence of FXa and the stability of actiten were then evaluated in re-calcified FX- or FVIII-deficient plasma samples (Figure 5A, B). As a control, pdFXa shortened the spontaneous clotting time of these plasma samples to $11 \pm 8.5 \mathrm{~min}$ and $6.7 \pm 2.9 \mathrm{~min}$, respectively. The presence of pdFX in FX-deficient plasma or rFVIII in FVIII-deficient plasma allowed the plasma to clot in $60 \pm 35 \mathrm{~min}$ and $25 \pm 8.7 \mathrm{~min}$, respectively. The time to clot in the presence of actiten was much longer in both plasma samples $(96 \pm 47 \mathrm{~min}$ and $>120 \mathrm{~min}$, respectively). This result further confirms the absence of contaminating FXa and did not reveal any instability of actiten in different plasma samples.

\section{In vitro evaluation of actiten potency}

Thrombin generation assays were performed to evaluate the ability of actiten to correct coagulation factor deficiencies. In all experiments, the deficient plasma was evaluated as a negative control and a pool of lyophilized normal plasma as a positive control. The thrombin generation parameters of normal plasma were chosen as a reference and compared with the parameters from deficient plasmas spiked with $20 \mu \mathrm{g} / \mathrm{mL}$ actiten (Table 1).

In FVIII-deficient plasma, a dose-response relation was observed for actiten from 10 to $60 \mu \mathrm{g} / \mathrm{mL}$ before saturation at $120 \mu \mathrm{g} / \mathrm{mL}$ (Figure $6 \mathrm{~A}$ ). At $20 \mu \mathrm{g} / \mathrm{mL}$ of actiten, the

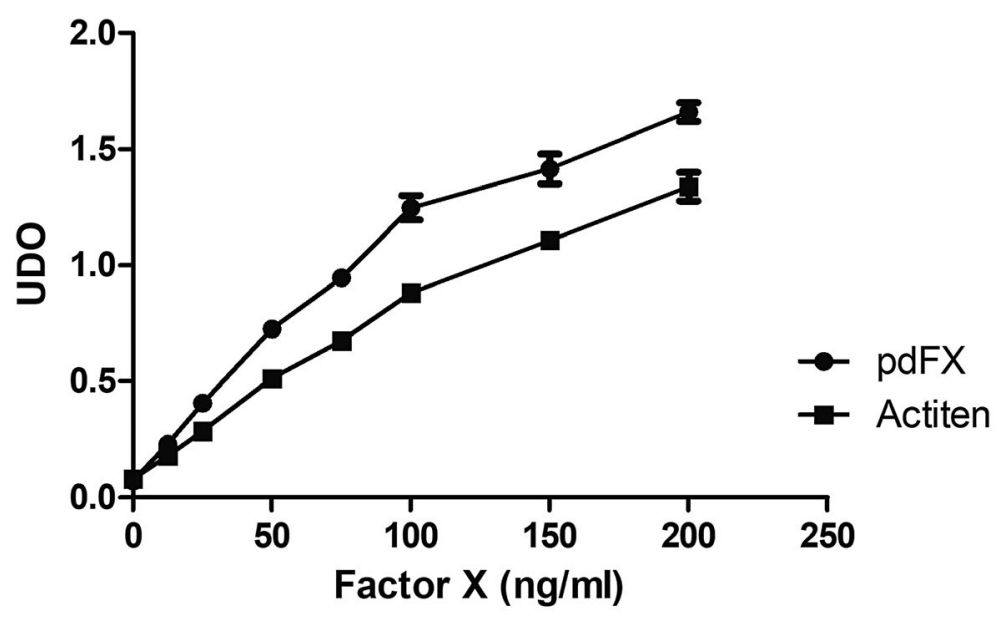

Figure 3. Binding of plasma-derived factor $X$ and actiten to phospholipids. Plasma-derived factor $X$ $(\mathrm{pdFX})(\bullet)$ and actiten $(\boldsymbol{\bullet})$ were incubated at increasing concentrations on coated phospholipids and detected by a polyclonal anti-FX coupled to horse radish peroxidase. $(n=4)$. UDO: optical density unit.

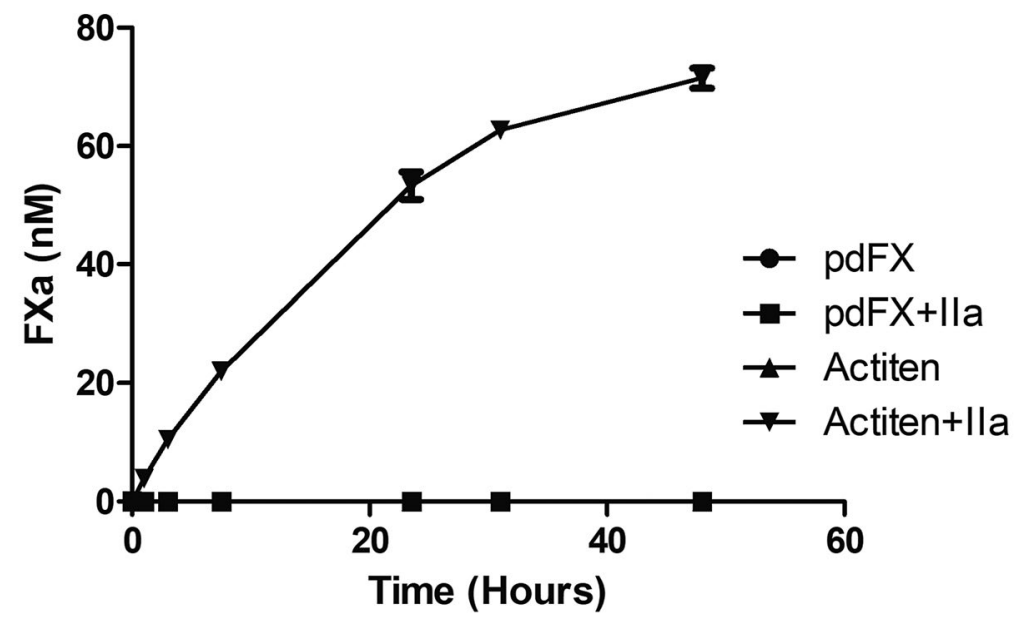

Figure 4. Activation of plasma-derived factor $X$ and actiten by thrombin. Plasma-derived factor $X$ $(\mathrm{pdFX})(100 \mathrm{nM})$ with $10 \mathrm{nM}$ thrombin (匹) or without thrombin $(\bullet)$, and actiten $(100 \mathrm{nM})$ with $10 \mathrm{nM}$ thrombin $(\boldsymbol{\nabla})$ or without thrombin $(\boldsymbol{\Delta})$ were incubated without phospholipid (PL) for increasing periods of time. At different time points a sample was taken and the presence of activated factor X (FXa) was measured. The results are representative of three independent experiments. Signs for pdFX without thrombin $(\bullet)$ and actiten without thrombin $(\boldsymbol{\Delta})$ are masked by $(\boldsymbol{\bullet})$." 
amount of actiten generated was greater than that in normal plasma (endogenous thrombin potential: $1819 \pm 202 v s$. $1510 \pm 216$ nM.min, respectively) although this was not a statistically significant difference. There was a slight increase in the lag time when actiten was used $(10.2 \pm 1.1$ min for actiten vs. $7.2 \pm 1.7$ min for normal plasma; $P<0.01$ ). Actiten was then evaluated in hemophilia A plasma with or without a high titer of inhibitors (292 BU/mL) (Figure $6 \mathrm{~B}, \mathrm{C})$. In this latter plasma, the addition of actiten, unlike that of FVIII, could restore thrombin generation in a dosedependent manner. At a dose of $20 \mu \mathrm{g} / \mathrm{mL}$, a total amount of $689 \pm 24 \mathrm{nM}$.min of thrombin was generated, providing significant correction of the plasma.

Actiten was next evaluated in FIX-deficient plasma, spiked or not with anti-FIX polyclonal antibodies, in which it behaved similarly as in the hemophilia A plasma or FVIII-deficient plasma (Figure 6D, E; Table 1). The potency of the molecule was then assessed in the absence of FX or FXI (Figure 6F, G). The behavior of the molecule was similar to that previously observed, with the amount

A

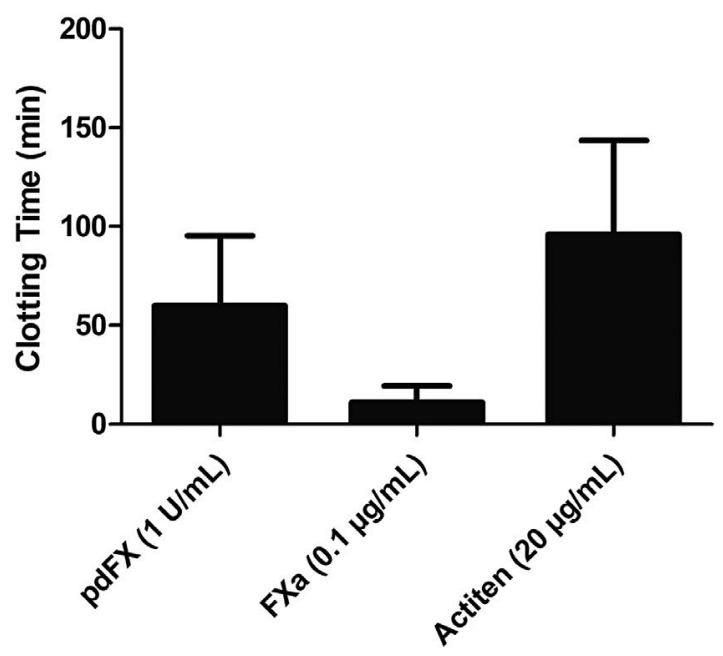

B

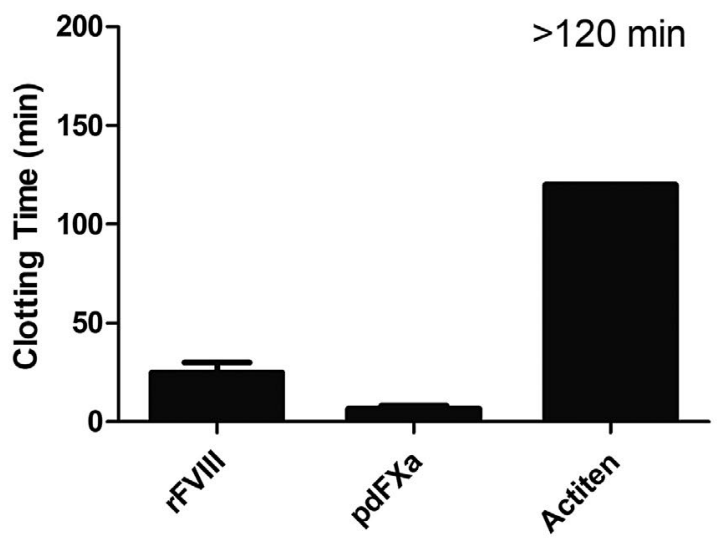

Figure 5. Evaluation of the stability of actiten in factor-deficient plasma samples. (A) Evaluation in factor X (FX)-deficient plasma. Plasma-derived FX (pdFX) $(10 \mu \mathrm{g} / \mathrm{mL}), \operatorname{pdFX}(10 \mu \mathrm{g} / \mathrm{mL})$ plus plasma-derived activated factor X (pdFXa) $(0.1 \mu \mathrm{g} / \mathrm{mL})$ and actiten $(20 \mu \mathrm{g} / \mathrm{mL})$ were incubated in FX-deficient plasma recalcified by $7.5 \mathrm{mM} \mathrm{CaCl}_{2}$. Plasma clotting times were recorded manually $(n=2$ 4). (B) Evaluation in factor VIII (FVIII)-deficient plasma. FVIII $(1 \mathrm{U} / \mathrm{mL})$, pdFXa (0.1 $\mu \mathrm{g} / \mathrm{mL})$ and actiten $(20 \mu \mathrm{g} / \mathrm{mL})$ were incubated in FVIII-deficient plasma re-calcified by $7.5 \mathrm{mM} \mathrm{CaCl}_{2}$. Plasma clotting times were recorded manually $(n=3)$. of thrombin generated $(1010 \pm 73 \mathrm{nM}$.min and $1285 \pm 119$ nM.min, respectively) being close to that in normal plasma (1510 \pm 216 nM.min) but again with an increased lag time compared to that of normal plasma $(12.1 \pm 1.8 \mathrm{~min}$ and 18.6 \pm 8.7 min vs. $7.2 \pm 1.7 \mathrm{~min} ; P<0.001$ and $P<0.001$, respectively).

It should be stressed that in all these thrombin generation assays, the thrombin generated was efficiently controlled by the anticoagulant system and that no runaway of coagulation was detected at up to $120 \mu \mathrm{g} / \mathrm{mL}$ actiten. These data indicate that even following clotting induction, actiten did not overreact or escape the anticoagulation pathway.

\section{In vivo evaluation of actiten potency}

A rabbit model of hemophilia A was established to evaluate the potency of actiten in vivo. A cocktail of two antiFVIII monoclonal antibodies severely impaired thrombin generation in rabbit plasma (Figure 7A). An in vivo assay was designed and is schematically represented in Figure 7B. The anti-FVIII antibodies or $\mathrm{NaCl}$ were infused into rabbits and the bleeding times were recorded. A statistically significant difference was observed between rabbits administered $\mathrm{NaCl}$ or anti-FVIII $(405 \pm 44$ s vs. $2760.5 \pm 348$ s; $P<0.01$ ), which validated the animal model (Figure 7C). The experiments were repeated but with the infusion of actiten, recombinant wild-type FX (recFX-WT) or $\mathrm{NaCl}$ following the infusion of anti-FVIII antibodies. RecFX-WT was produced from HEK293F cells and purified in the same way as actiten (Online Supplementary Figure S3). As a positive control, FVIIa $(500 \mu \mathrm{g} / \mathrm{kg}$ ) was shown to correct bleeding in this model $(746 \pm 290 \mathrm{~s} ; P<0.01)$ following its infusion. The bleeding times in anti-FVIII-treated rabbits $(2861 \pm 2 \mathrm{~s})$ were significantly longer than those in actitentreated rabbits $(P<0.05)$; bleeding times of the latter were similar to those in untreated wild-type rabbits $(387 \pm 111 \mathrm{~s}$ vs. $347 \pm 51 \mathrm{~s}$, respectively; $P=$ ns) (Figure $7 D$ ). In contrast, the infusion of recFX-WT did not diminish the bleeding time with regard to those of anti-FVIII-treated rabbits ( $2847 \pm 668$ s vs. $2861 \pm 2$ s; $P=$ ns) confirming the absence of contaminating $\mathrm{FXa}$ in the preparation and the specificity of actiten (Online Supplementary Figure S3). The hemoglobin losses were also compared and identical efficacy profiles were found: rabbits treated with actiten lost the equivalent of $4 \pm 2 \mathrm{mg} / \mathrm{dL}$ hemoglobin; in contrast, the antiFVIII-treated rabbits lost the equivalent of $268 \pm 169 \mathrm{mg} / \mathrm{dL}$ $(P<0.05)$ (Figure 7E). Recombinant FVIIa diminished the loss of hemoglobin $(61 \pm 38 \mathrm{mg} / \mathrm{mL})$ in contrast to recFXWT $(420 \pm 222 \mathrm{mg} / \mathrm{mL}, P=\mathrm{ns})$. Markers of exaggerated coagulation (thrombin/antithrombin complexes, prothrombin fragment 1 and 2 and fibrinogen $\mathrm{D}$-dimers) were also measured but none of them was significantly increased (Online Supplementary Table S1). These results demonstrate that actiten was able to restore coagulation in vivo, in a model of antibody-induced hemophilia A.

\section{Discussion}

Actiten as a NRF strategy has some specific features that are illustrated by the data presented here. First, actiten was able to normalize the amount of thrombin generated in vitro as well as in vivo during bleeding in a model of antibody-induced hemophilia A. In contrast, most of the other NRF strategies partially restore coagulation but some 
Table 1. Thrombin generation parameters of normal and factor-deficient plasma samples, containing inhibitors or not, supplemented with actiten.

\begin{tabular}{|c|c|c|c|c|c|c|c|c|c|c|c|c|c|c|c|}
\hline $\begin{array}{l}\text { TG } \\
\text { Parameter }\end{array}$ & $\begin{array}{l}\text { Normal } \\
\text { plasma } \\
\text { TF/PL } \\
(n=13) \\
+ \text { buffer }\end{array}$ & $\begin{array}{l}\text { FVIII-def } \\
\text { plasma } \\
\text { TF/PL } \\
\text { (n=5) } \\
\text { + buffer }\end{array}$ & $\begin{array}{l}\text { FVIII-def } \\
\text { plasma } \\
\text { TF/PL } \\
\text { (n=5) } \\
+ \text { actiten }\end{array}$ & $\begin{array}{l}\text { Hem.A } \\
\text { TF/PL } \\
(n=3)\end{array}$ & $\begin{array}{l}\text { Hem.A } \\
\text { TF/PL } \\
(n=5)\end{array}$ & $\begin{array}{c}\text { Hem. A } \\
+ \text { inhibit. } \\
\text { TF/PL } \\
\text { (n=3) } \\
\text { + buffer }\end{array}$ & $\begin{array}{c}\text { Hem. A } \\
+ \text { inhibit. } \\
\text { TF/PL } \\
\text { (n=3) } \\
\text { + actiten }\end{array}$ & $\begin{array}{l}\text { FIX-def } \\
\text { plasma } \\
\text { TF/PL } \\
(n=2) \\
+ \text { buffer }\end{array}$ & $\begin{array}{c}\text { FIX-def } \\
\text { plasma } \\
\text { TF/PL } \\
(n=4)\end{array}$ & $\begin{array}{c}\text { FIX-def } \\
\text { plasma + } \\
\text { inhilbit. } \\
\text { TF/PL } \\
(n=2) \\
\text { + buffer }\end{array}$ & $\begin{array}{c}\text { FIX-def } \\
\text { plasma + } \\
\text { inhibit. } \\
\text { TF/PL } \\
(n=4) \\
+ \text { actiten }\end{array}$ & $\begin{array}{l}\text { FX-def } \\
\text { plasma } \\
\text { TF/PL } \\
\text { (n=3) } \\
+ \text { buffer }\end{array}$ & $\begin{array}{l}\text { FX-def } \\
\text { plasma } \\
\text { TF/PL } \\
(n=6)\end{array}$ & $\begin{array}{l}\text { FXI-def } \\
\text { plasma } \\
\text { TF/PL } \\
(n=2)\end{array}$ & $\begin{array}{c}\text { FXI-def } \\
\text { plasma } \\
\text { TF/PL } \\
(n=4)\end{array}$ \\
\hline $\begin{array}{l}\text { Lagtime } \\
\text { (min) }\end{array}$ & $\begin{array}{c}7.2 \\
\pm 1.7\end{array}$ & $\begin{array}{c}8.7 \\
\pm 1.4\end{array}$ & $\begin{array}{l}10.2 \\
\pm 1.1\end{array}$ & $\begin{array}{c}5.3 \\
\pm 2.2\end{array}$ & $\begin{array}{l}7.7 \\
\pm 1.6\end{array}$ & $\begin{array}{c}7.1 \\
\pm 0.8\end{array}$ & $\begin{array}{c}9.2 \\
\pm 0.9\end{array}$ & $\begin{array}{c}8.2 \\
\pm 4.8\end{array}$ & $\begin{array}{l}16.2 \\
\pm 6.1\end{array}$ & $\begin{array}{c}8.6 \\
\pm 4.1\end{array}$ & $\begin{array}{r}12.8 \\
\pm 3.1\end{array}$ & $\begin{array}{l}31.3 \\
\pm 6.3\end{array}$ & $\begin{array}{l}12.1 \\
\pm 1.8\end{array}$ & $\begin{array}{r}10.7 \\
\pm 3.3\end{array}$ & $\begin{array}{l}18.6 \\
\pm 8.7\end{array}$ \\
\hline $\begin{array}{l}\text { ETP } \\
\text { (nM.min IIa) }\end{array}$ & $\begin{array}{r}1510 \\
\pm 216\end{array}$ & $\begin{array}{l}543 \\
\pm 77\end{array}$ & $\begin{array}{r}1819 \\
\pm 202\end{array}$ & $\begin{array}{l}213 \\
\pm 22\end{array}$ & $\begin{array}{c}812 \\
\pm 243\end{array}$ & $\begin{array}{r}199 \\
\pm 3.0\end{array}$ & $\begin{array}{l}689 \\
\pm 24\end{array}$ & $\begin{array}{l}155 \\
\pm 56\end{array}$ & $\begin{array}{l}1436 \\
\pm 101\end{array}$ & $\begin{array}{c}186 \\
\pm 263\end{array}$ & $\begin{array}{l}1394 \\
\pm 87\end{array}$ & $\begin{array}{c}0 \\
\pm 0\end{array}$ & $\begin{array}{l}1010 \\
\pm 73\end{array}$ & $\begin{array}{l}430 \\
\pm 29\end{array}$ & $\begin{array}{l}1285 \\
\pm 119\end{array}$ \\
\hline $\begin{array}{l}\text { Peak } \\
\text { (nM Ila) }\end{array}$ & $\begin{array}{l}195 \\
\pm 87\end{array}$ & $\begin{array}{l}19.6 \\
\pm 4.0\end{array}$ & $\begin{array}{l}224 \\
\pm 59\end{array}$ & $\begin{array}{l}11.9 \\
\pm 2.3\end{array}$ & $\begin{array}{c}81.3 \\
\pm 31.4\end{array}$ & $\begin{array}{c}9.4 \\
\pm 0.3\end{array}$ & $\begin{array}{c}76 \\
\pm 11\end{array}$ & $\begin{array}{c}5.3 \\
\pm 2.7\end{array}$ & $\begin{array}{l}168 \\
\pm 34\end{array}$ & $\begin{array}{c}9.5 \\
\pm 10.2\end{array}$ & $\begin{array}{l}157 \\
\pm 30\end{array}$ & $\begin{array}{c}0,3 \\
\pm 0.1\end{array}$ & $\begin{array}{l}119 \\
\pm 34\end{array}$ & $\begin{array}{r}19.0 \\
\pm 3.5\end{array}$ & $\begin{array}{l}146 \\
\pm 52\end{array}$ \\
\hline $\begin{array}{l}\text { ttPeak } \\
\text { (min) }\end{array}$ & $\begin{array}{r}12.1 \\
\pm 2.6\end{array}$ & $\begin{array}{l}25.7 \\
\pm 2.1\end{array}$ & $\begin{array}{l}15.5 \\
\pm 2.7\end{array}$ & $\begin{array}{l}17.0 \\
\pm 7.4\end{array}$ & $\begin{array}{r}15.6 \\
\pm 1.2\end{array}$ & $\begin{array}{r}22.9 \\
\pm 0.8\end{array}$ & $\begin{array}{l}16.8 \\
\pm 0.8\end{array}$ & $\begin{array}{c}28.2 \\
\pm 12.3\end{array}$ & $\begin{array}{l}23.1 \\
\pm 6.6\end{array}$ & $\begin{array}{c}35 \\
\pm 26\end{array}$ & $\begin{array}{r}19.5 \\
\pm 3.0\end{array}$ & $\begin{array}{l}42.6 \\
\pm 4.0\end{array}$ & $\begin{array}{r}17.9 \\
\pm 1.4\end{array}$ & $\begin{array}{l}21.7 \\
\pm 4.2\end{array}$ & $\begin{array}{l}25.6 \\
\pm 10.3\end{array}$ \\
\hline $\begin{array}{l}\text { StartTail } \\
\text { (min) }\end{array}$ & $\begin{array}{l}32.9 \\
\pm 6.1\end{array}$ & $\begin{array}{l}67.8 \\
\pm 6.8\end{array}$ & $\begin{array}{l}38.8 \\
\pm 6.6\end{array}$ & $\begin{array}{c}48 \\
\pm 11\end{array}$ & $\begin{array}{l}35.5 \\
\pm 2.3\end{array}$ & $\begin{array}{l}53,8 \\
\pm 1.2\end{array}$ & $\begin{array}{l}33.0 \\
\pm 2.2\end{array}$ & $\begin{array}{l}63.5 \\
\pm 11\end{array}$ & $\begin{array}{l}40.9 \\
\pm 6.9\end{array}$ & $\begin{array}{c}28 \\
\pm 39\end{array}$ & $\begin{array}{l}39.0 \\
\pm 4.4\end{array}$ & $\begin{array}{c}18.7 \\
\pm 32.3\end{array}$ & $\begin{array}{l}37.6 \\
\pm 4.1\end{array}$ & $\begin{array}{c}57 \\
\pm 19.8\end{array}$ & $\begin{array}{l}44.6 \\
\pm 12.2\end{array}$ \\
\hline $\begin{array}{l}\text { Velocity } \\
\text { (nM IIa/min) }\end{array}$ & $\begin{array}{c}40.4 \\
\pm 25.4\end{array}$ & $\begin{array}{c}1.1 \\
\pm 0.25\end{array}$ & $\begin{array}{c}48.3 \\
\pm 22.8\end{array}$ & $\begin{array}{c}1.2 \\
\pm 0.6\end{array}$ & $\begin{array}{l}10.7 \\
\pm 5.3\end{array}$ & $\begin{array}{c}0.6 \\
\pm 0.1\end{array}$ & $\begin{array}{l}10.1 \\
\pm 2.5\end{array}$ & $\begin{array}{c}0.3 \\
\pm 0.2\end{array}$ & $\begin{array}{l}25.2 \\
\pm 8.7\end{array}$ & $\begin{array}{c}0.8 \\
\pm 1.0\end{array}$ & $\begin{array}{l}25.2 \\
\pm 8.7\end{array}$ & $\begin{array}{c}0.1 \\
\pm 0.01\end{array}$ & $\begin{array}{l}21.8 \\
\pm 9.7\end{array}$ & $\begin{array}{c}1.7 \\
\pm 0.2\end{array}$ & $\begin{array}{l}23.3 \\
\pm 13.4\end{array}$ \\
\hline
\end{tabular}

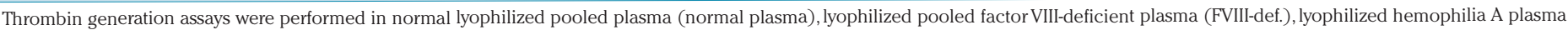

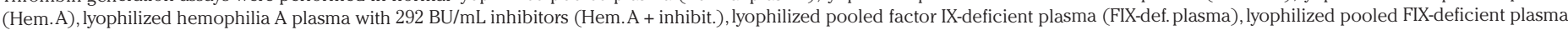

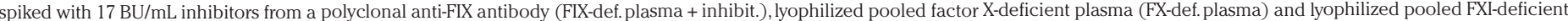

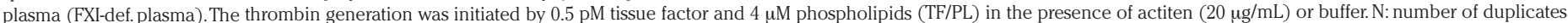
performed.

bleeding continues to occur. Second, it is based on the use of a zymogen thereby being a unique strategy respecting the coagulation/anticoagulation balance. Actiten liberates a wild-type FXa, a natural target of the anticoagulation system for which antithrombin could easily be used as an antidote, if needed. Third, as the duration of the treatment is based on the half-life of FX, this strategy can offer a four-fold longer persistence of treatment efficacy than that using FVIII. Lastly, actiten was demonstrated to be active in several coagulation defects, offering a supplementary therapeutic option for rare coagulation defects such as hemophilia B with inhibitors (Figure 6E).

In order to generate actiten, the cleavage site liberating the activation peptide was targeted to change the recognition of FX. The addition of the 10 -amino acid peptide offers the possibility of two cleavage sites during actiten activation. As observed by mass spectroscopy following RVV-X cleavage, only the activation peptide containing the complete added peptide was detected, suggesting a preferential cleavage between LDRP and IVV from the heavy chain. Moreover, there was no loss in the activity of the FXa liberated from actiten with regard to pdFXa. These data confirm that the active species liberated corresponds to a wild-type FXa.

The modification of activation was demonstrated since the presence of thrombin allowed the generation of FXa from actiten but not pdFX. Importantly, the recognition of the molecule by the FVIIa/TF complex was minimally affected and still allowed efficient participation of actiten in the initiation of the coagulation leading to the generation of primary traces of FXa and thrombin. The ability of the molecule to correct FX-deficient plasma confirmed that the activation of actiten by FVIIa/TF was sufficient to replace the endogenous FX. In contrast, the important loss of activation by the FVIIIa/FIXa complex is less crucial for the function of actiten in hemophilia since the molecule is designed to substitute for their absence.
In vitro, actiten showed a velocity, a peak height and an endogenous thrombin potential sufficient to correct factordeficient plasma samples. However, an increased lag time to clotting was observed in all factor-deficient samples of plasmas. This delay likely results from: (i) the moderate loss of FVIIa/TF recognition to activate the molecule; (ii) activation by thrombin that might not be as efficient as natural initiation of coagulation; and/or (iii) the time required to generate the first traces of thrombin to amplify the coagulation. ${ }^{22}$ Nevertheless, this delay did not translate in vivo into a lack of efficiency since the presence of actiten allowed clotting in antibody-treated rabbits with the same kinetics as in wild-type animals. Factor V contained within platelets actively participates in the generation of thrombin through the prothrombinase complex..$^{23-25}$ Thus, in vivo, there may be some elements favoring clotting, such as factor $\mathrm{V}$ and platelets, that are lacking from the in vitro assays. The presence of such elements might reinforce the clotting efficiency of actiten and eliminate differences in lag time, compared to that in normal plasma, observed in vitro.

To evaluate actiten in vivo, a rabbit model was established since human FXa is equally efficient in rabbit and human plasma. ${ }^{26}$ The classic hemophilia A mouse model would have been preferred to evaluate the efficacy of actiten, but the compound is less efficient in mouse plasma, rendering this model poorly predictive (data not shown). Despite the fact that the pair of monoclonal antibodies severely impaired rabbit coagulation in vitro, a limitation of the model is that it was not possible to ascertain full FVIII inhibition in vivo.

It has been reported that the half-life of FXa in blood is extremely short $(<1.5 \mathrm{~min}) .{ }^{27}$ In our in vivo model, the rabbit nail cuticle was cut $35 \mathrm{~min}$ after infusion of the molecule. The occurrence of normal clotting at this time point demonstrated that the molecule was kept under a zymogen form in the circulation and that it was mobilized when needed. 
Mutated factor $X$ to correct hemophilias

A

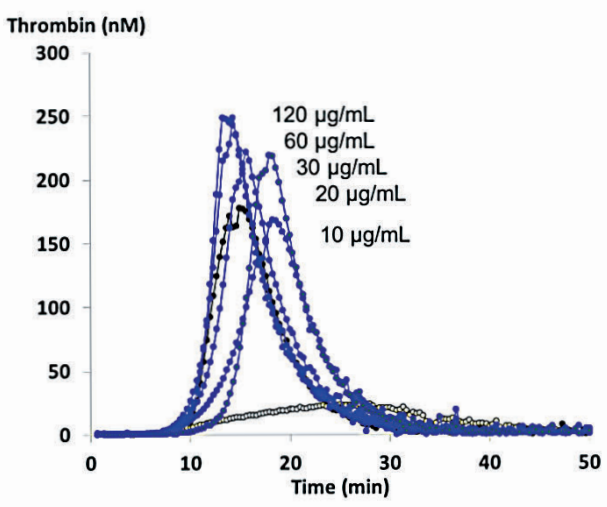

C

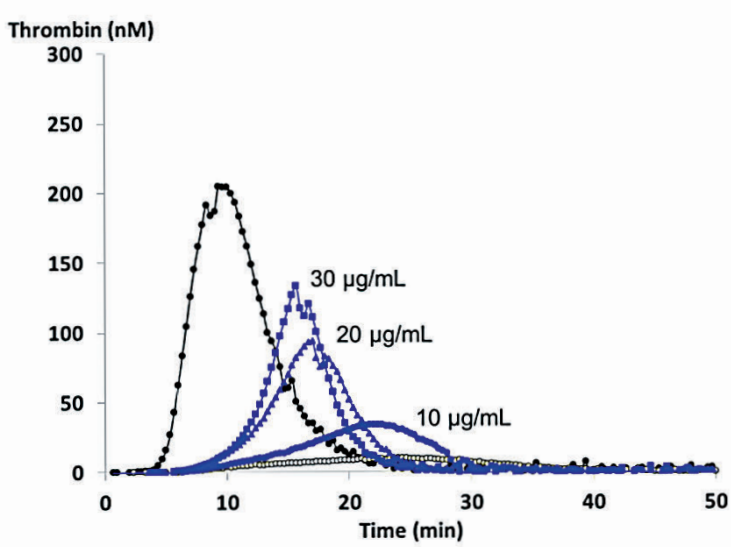

$\mathbf{E}$

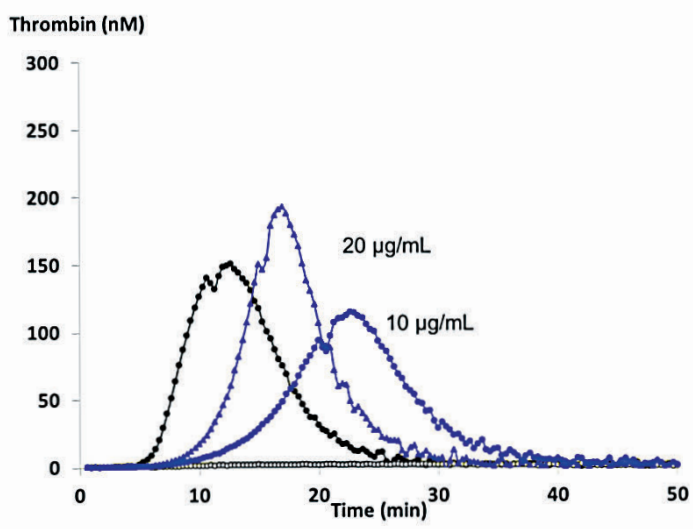

G

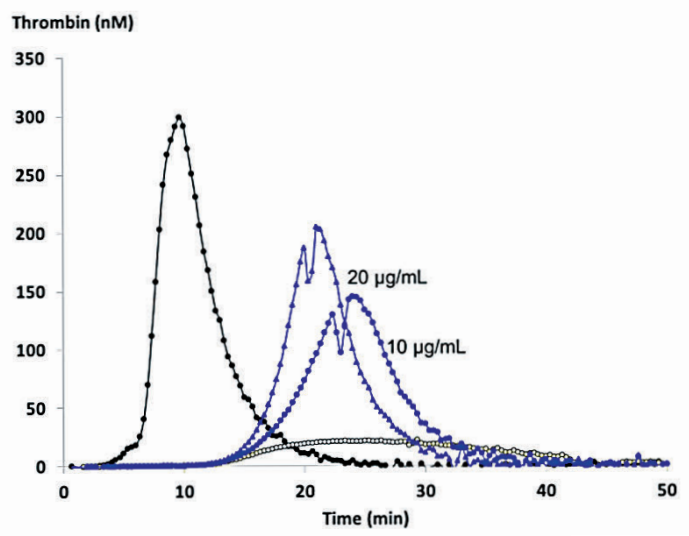

B

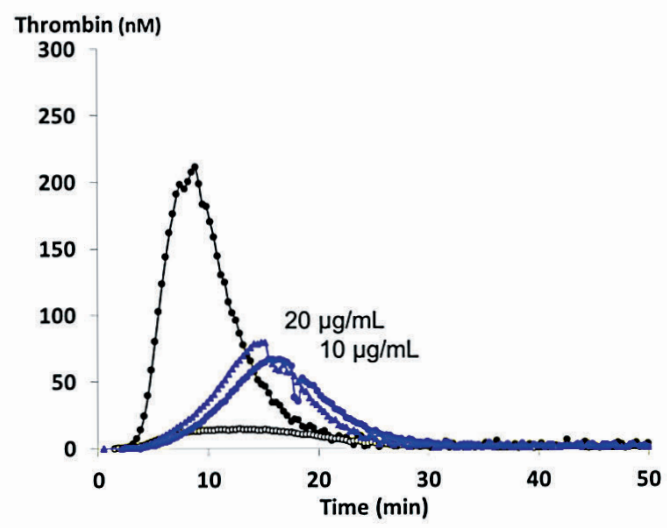

D

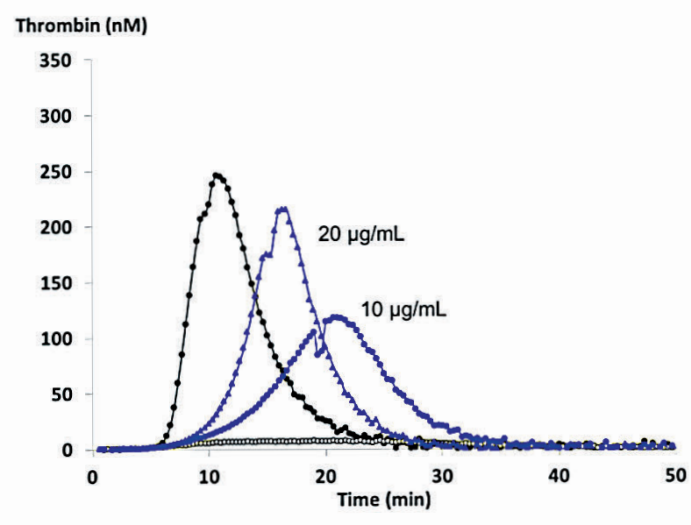

$\mathrm{F}$

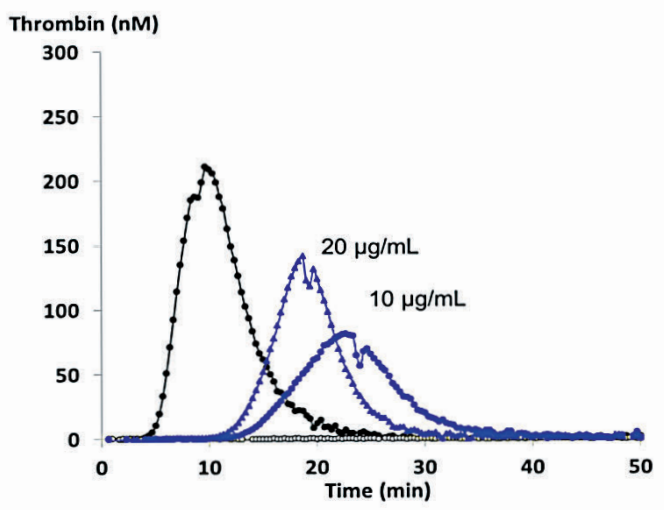

Figure 6. Evaluation of actiten potency in several factor-deficient or homophilia plasma samples. Each plasma sample was activated by $0.5 \mathrm{pM}$ thissue factor and $4 \mu \mathrm{M}$ phospholipids. For all panels, the following representsions are used: normal plasma $(\bullet)$, deficient plasma (०). (A) Actiten potency was evaluated at different concentrations $(10 \rightarrow 120 \mu \mathrm{g} / \mathrm{mL})$ in factor VIII (FVIII)-deficient plasma (blue $\bullet$ ). (B) Actiten potency was evaluated at 10 or $20 \mu \mathrm{g} / \mathrm{mL}$ (blue $\bullet, \boldsymbol{\Delta}$, respectively) in hemophilia A plasma. (C) Actiten potency was evaluated at different concentrations $(10 \rightarrow 30 \mu \mathrm{g} / \mathrm{mL}$, blue $\bullet$, $\boldsymbol{\Lambda}, \mathbf{m}$, respectively) in hemophilia A plasma with $292 \mathrm{BU} / \mathrm{mL}$. (D) Actiten potency was evaluated at 10 and $20 \mu \mathrm{g} / \mathrm{mL}$ (blue $\bullet, \boldsymbol{\Lambda}$, respectively) in factor IX (FIX)-deficient plasma. (E) Actiten potency was evaluated at 10 and 20 $\mu \mathrm{g} / \mathrm{mL}$ (blue $\bullet, \boldsymbol{\Delta}$, respectively) in FIX-deficient plasma with spiked anti-FIX inhibitors $(17 \mathrm{BU} / \mathrm{mL})$. ( $F)$ Actiten potency was evaluated at 10 and 20 $\mu \mathrm{g} / \mathrm{mL}$ (blue $\bullet, \boldsymbol{\Lambda}$, respectively) in factor $X(F X)$-deficient plasma. (G) Actiten potency was evaluated at 10 and $20 \mu \mathrm{g} / \mathrm{mL}$ (blue $\bullet, \boldsymbol{\Lambda}$, respectively) in factor XI (FXI)-deficient plasma. The data are derived from duplicate evaluatons and are representative of 2-13 independent assays.

haematological | 2020; 105(9)

2341 
A

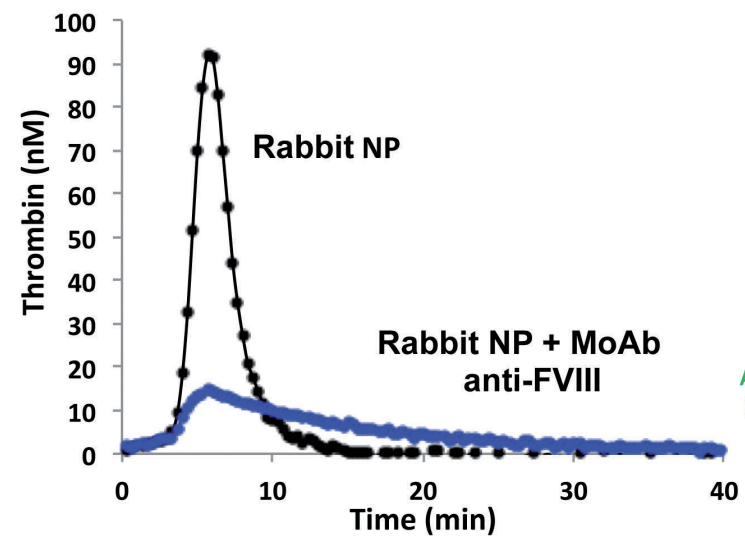

B

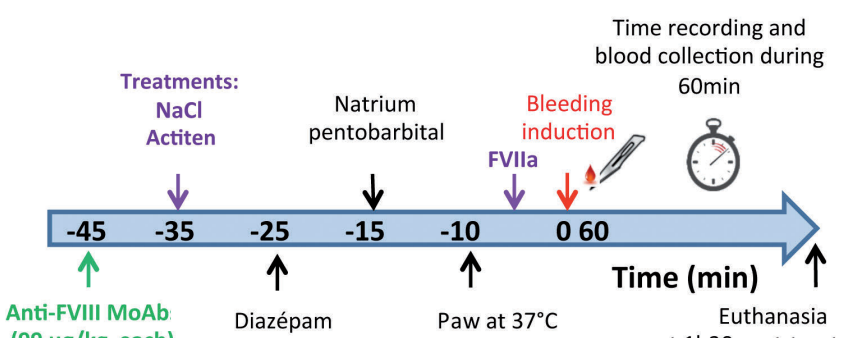

at $1 \mathrm{~h} 30$ post-treatment
C

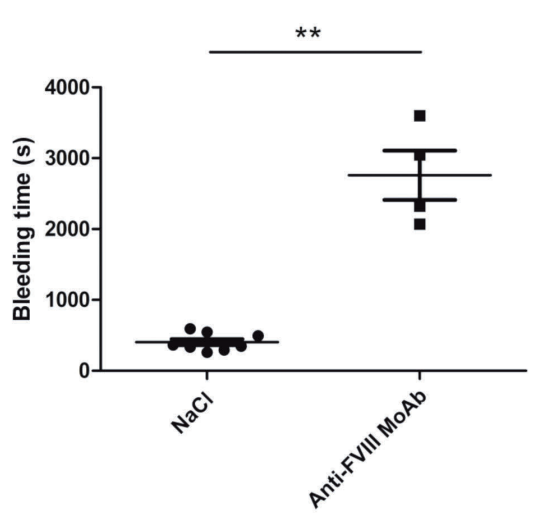

D

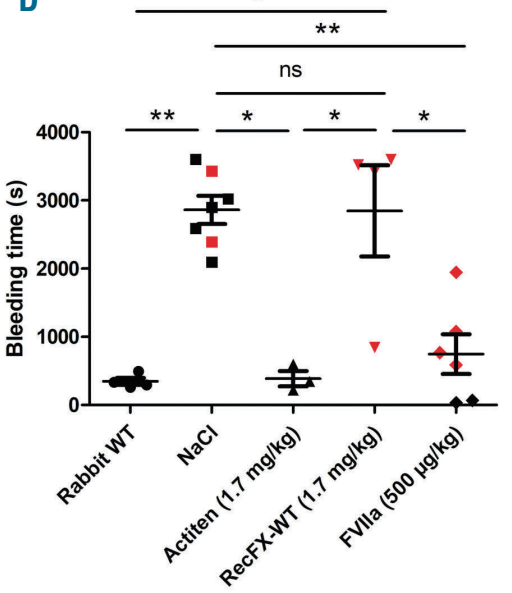

E

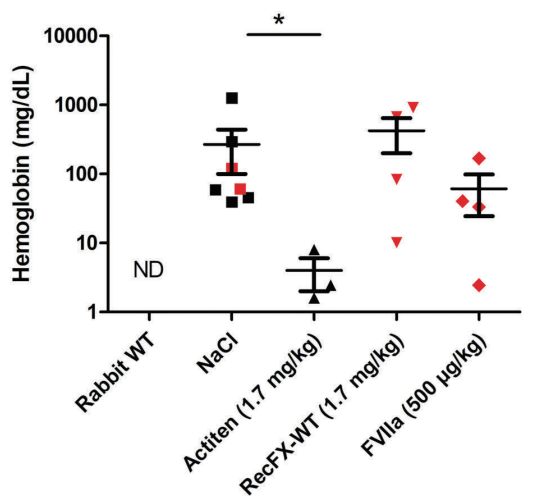

Figure 7. In vivo evaluation of actiten in a rabbit model of antibody-induced hemophilia A. (A) In vitro control of the efficiency of anti-factor VIII (FVIII) antibodies. Thrombin generation was induced by tissue factor/phospholipids in rabbit normal plasma (NP) in the presence or absence of anti-FVIII inhibitors (3 $\mu \mathrm{g} / \mathrm{mL}$ each). (B) Schematic representation of the in vivo protocol. The rabbit's paw is placed in phosphate-buffered saline at $37^{\circ} \mathrm{C}$ to measure time to clot and to collect blood loss. (C) Evaluation of rabbit bleeding following infusion of anti-FVIII antibodies. Bleeding times were recorded in rabbits infused with NaCl ( $n=8$ ) or anti-FVIII antibodies $(99 \mu \mathrm{g} / \mathrm{kg}$ each; $\mathrm{n}=4)$ following a nail cuticle cut. Data are presented as the means \pm standard error of mean (SEM) and are representative of at least two separate experiments. (D) Evaluation of actiten potency in rabbits infused with anti-FVIII inhibitors. Bleeding times were recorded from rabbit controls ( $\mathrm{n}=4$ ), rabbits infused with anti-FVIII inhibitors and $\mathrm{NaCl}(\mathrm{n}=7)$ or actiten $(1.7 \mathrm{mg} / \mathrm{kg}, \mathrm{n}=3)$ or recombinant wildtype factor $\mathrm{X}$ (recFX-WT) $(1.7 \mathrm{mg} / \mathrm{kg}, \mathrm{n}=4)$ or recombinant activated factor VII (recFVIla) $(500 \mu \mathrm{g} / \mathrm{kg}, \mathrm{n}=6)$ following a nail cuticle cut. (E) Hemoglobin loss from rabbits infused with anti-FVIII inhibitors and $\mathrm{NaCl}(\mathrm{n}=7)$ or actiten $(1.7 \mathrm{mg} / \mathrm{kg}, \mathrm{n}=3)$ or recFX-WT $(1.7 \mathrm{mg} / \mathrm{kg}, \mathrm{n}=4)$ or recFVlla $(500 \mu \mathrm{g} / \mathrm{kg}, \mathrm{n}=4)$. Data are presented as the means \pm SEM (statistical significance: $n s$ : not significant; $* P<0.05$, $* * P<0.01$ ). (D, E) Experiments were performed in two distinct rounds that are identified by the marker color. NP: normal plasma; MoAb: monoclonal antibodies; ND, not done.

The advantages of actiten include the interesting possibility that it could be used to correct various coagulation disorders. At a dose close to the physiological concentrations of FX, actiten normalizes clotting in FVIII-, FIX-, FX- and FXI-deficient plasma samples, independently of the presence of anti-FVIII or anti-FIX inhibitors. Thrombin generation assays performed in rabbit plasma were found to be remarkably predictive to determine the efficient dose of anti-FVIII antibodies, the effective concentrations of actiten and to help in the design of the in vivo assay. On the basis of this experience, corrections of the other coagulation defects observed in factor-deficient plasma samples would likely be confirmed in vivo in other preclinical models. Whereas the hemophilia A and B markets stimulate the research for innovative treatments, this is not true for FX and FXI deficiencies. Recently, a recombinant version of FX was offered to patients whereas FXI deficiency can only be treated by a few plasma-derived products. ${ }^{28,29}$ Given its limited activa- tion by the tenase complex, it could be expected that replacing FX by actiten might be less efficient than replacing it with natural FX, despite promising in vitro data. Nevertheless, if the in vivo potential of actiten turns out to be satisfactory, the compound could offer a supplementary treatment option for these rare diseases.

Modifying the specificity of FX could induce a risk of thrombogenicity. However, no sign of such a drawback has been identified so far. In vitro incubation of the molecule in FVIII- and FX-deficient plasma samples without induction led to clotting at later times than when the samples were spiked with the missing factors. In all the thrombin generation assays performed, once the coagulation was initiated it was systematically controlled by the anticoagulation system since all peaks returned to baseline. In vivo, the rabbits showed no clinical signs of suffering and the markers of thrombosis measured remained at baseline levels. In addition, the infusion of actiten (at 0.33 
$\mathrm{mg} / \mathrm{kg}$ ) in wild-type rabbits did not lead to any sign of suffering suggesting that even in vivo in a blood normally prone to coagulate the molecule probably remains in the form of a zymogen (Online Supplementary Figure S2). Nevertheless, to confirm the safety of the molecule, more challenging in vivo models, such as the Wessler assay, are scheduled.

Another primary concern regarding any novel biologic is its potential to elicit an immune response. This can be investigated during product development although preliminary evaluations using in silico, in vitro and in vivo models are recognized to be not fully predictive..$^{30-32}$ Nevertheless, actiten was assessed by three independent in silico algorithms, and none identified any specific concern for its immunogenicity in comparison to that of pdFX (data not shown).

Emicizumab is the most advanced NRF and has some crucial advantages for patients, in particular for those who have developed inhibitors. ${ }^{14}$ However, some patients treated with this compound still experienced bleeding whereas others developed anti-drug antibodies. Thus, there is still a need for alternative therapies with different mechanisms of action to improve patients' care. The in vitro and in vivo data presented here validate the concept of re-directing the FX specificity to bypass the need for FVIII and FIX and may offer an additional opportunity to correct bleeding in several coagulation defects even in the presence of inhibitors.

\section{Acknowledgments}

The authors thank Bianca Boussier, Sylvie Le Ver, Bénedicte Fournes and Paul Martres for their participation in the in vivo experiments, Sophie Lecompte for helping to correct the manuscript and Céline Bourdon for her technical help.

\section{References}

1. Mannucci PM, Tuddenham EG. The hemophilias--from royal genes to gene therapy. $\mathrm{N}$ Engl J Med. 2001;344(23):1773-1779.

2. Berntorp E, Shapiro AD. Modern haemophilia care. Lancet. 2012;379(9824): 1447-1456.

3. Ragni MV. New-generation recombinant factor concentrates: bridge to gene therapy. Haemophilia. 2001;7(Suppl 1):28-35.

4. Schlesinger KW, Ragni MV. Safety of the new generation recombinant factor concentrates. Expert Opin Drug Saf. 2002;1(3):213223

5. Lambert T, Benson G, Dolan G, et al. Practical aspects of extended half-life products for the treatment of haemophilia. Ther Adv Hematol. 2018;9(9):295-308

6. Schulte S. Half-life extension through albumin fusion technologies. Thromb Res. 2009;124(Suppl 2):S6-S8.

7. Hoy SM. Eftrenonacog alfa: a review in haemophilia B. Drugs. 2017;77(11):12351246.

8. Mahlangu J, Young G, Hermans C, Blanchette V, Berntorp E, Santagostino E. Defining extended half-life rFVIII - a critical review of the evidence. Haemophilia. 2018;24(3):348-358.

9. Sehgal A, Barros S, Ivanciu L, et al. An RNAi therapeutic targeting antithrombin to rebalance the coagulation system and promote hemostasis in hemophilia. Nat Med. 2015;21(5):492-497.

10. Chowdary P, Lethagen S, Friedrich U, et al. Safety and pharmacokinetics of anti-TFPI antibody (concizumab) in healthy volunteers and patients with hemophilia: a randomized first human dose trial. J Thromb Haemost. 2015;13(5):743-754.

11. Prince $R$, Bologna $L$, Manetti $M$, et al. Targeting anticoagulant protein $S$ to improve hemostasis in hemophilia. Blood. 2018;131(12):1360-1371.

12. Polderdijk SG, Adams TE, Ivanciu L, Camire RM, Baglin TP, Huntington JA. Design and characterization of an APC-specific serpin for the treatment of hemophilia. Blood. 2017;129(1):105-113

13. Kitazawa T, Igawa T, Sampei Z, et al. A bispecific antibody to factors IXa and $\mathrm{X}$ restores factor VIII hemostatic activity in a hemophilia A model. Nat Med. 2012;18 (10):1570-1574.

14. Oldenburg J, Mahlangu JN, Kim B, et al. Emicizumab prophylaxis in hemophilia A with inhibitors. N Engl J Med. 2017;377 (9):809-818.

15. Mahlangu J, Oldenburg J, Paz-Priel I, et al. Emicizumab prophylaxis in patients who have hemophilia A without inhibitors. N Engl J Med. 2018;379(9):811-822.

16. Louvain-Quintard VB, Bianchini EP, CalmelTareau C, Tagzirt M, Le Bonniec BF. Thrombin-activable factor $\mathrm{X}$ re-establishes an intrinsic amplification in tenase-deficient plasmas. J Biol Chem. 2005;280(50):4135241359.

17. Gueguen P, Cherel G, Badirou I, Denis CV, Christophe OD. Two residues in the activation peptide domain contribute to the halflife of factor $X$ in vivo. J Thromb Haemost. 2010;8(7):1651-1653.

18. Hemker HC, Beguin S. Thrombin generation in plasma: its assessment via the endogenous thrombin potential. Thromb Haemost. 1995;74(1):134-138.

19. Chevreux G, Tilly N, Faid V, Bihoreau N. Mass spectrometry based analysis of human plasma-derived factor X revealed novel posttranslational modifications. Protein Sci. 2015;24(10):1640-1648

20. Jesty J, Spencer AK, Nakashima Y, Nemerson Y, Konigsberg W. The activation of coagulation factor X. Identity of cleavage sites in the alternative activation pathways and characterization of the $\mathrm{COOH}$-terminal peptide. J Biol Chem. 1975;250(12):4497-4504

21. Mertens K, Bertina RM. Pathways in the activation of human coagulation factor X. Biochem J. 1980;185(3):647-658.

22. Dargaud Y, Wolberg AS, Luddington $\mathrm{R}$, et al. Evaluation of a standardized protocol for thrombin generation measurement using the calibrated automated thrombogram: an international multicentre study. Thromb
Res. 2012;130(6):929-934

23. Miletich JP, Majerus DW, Majerus PW. Patients with congenital factor $\mathrm{V}$ deficiency have decreased factor Xa binding sites on their platelets. J Clin Invest. 1978;62(4):824831.

24. Miletich JP, Jackson CM, Majerus PW. Properties of the factor Xa binding site on human platelets. J Biol Chem. 1978;253(19): 6908-6916.

25. Tracy PB, Giles AR, Mann KG, Eide LL, Hoogendoorn H, Rivard GE. Factor V (Quebec): a bleeding diathesis associated with a qualitative platelet factor $\mathrm{V}$ deficiency. J Clin Invest. 1984;74(4):1221-1228.

26. Grenier D, Samama MM, Chtourou S, Plantier J-L. Reverting Xarelto@ (rivaroxaban) effect by activated factor X: assessment using thrombin generation assay. Blood. 2014;124(21):2868.

27. Ivanciu $\mathrm{L}$, Toso $\mathrm{R}$, Margaritis $\mathrm{P}$, et al. A zymogen-like factor Xa variant corrects the coagulation defect in hemophilia. Nat Biotechnol. 2011;29(11):1028-1033.

28. Peyvandi F, Garagiola I, Biguzzi E. Advances in the treatment of bleeding disorders. J Thromb Haemost. 2016;14(11):2095-2106.

29. Bauduer F, de RE, Boyer-Neumann C, et al. Factor XI replacement for inherited factor XI deficiency in routine clinical practice: results of the HEMOLEVEN prospective 3-year postmarketing study. Haemophilia. 2015;21 (4):481-489.

30. Bryson CJ, Jones TD, Baker MP. Prediction of immunogenicity of therapeutic proteins: validity of computational tools. BioDrugs. 2010;24(1):1-8

31. Mahlangu JN, Weldingh KN, Lentz SR, et al. Changes in the amino acid sequence of the recombinant human factor VIIa analog, vatreptacog alfa, are associated with clinical immunogenicity. J Thromb Haemost. 2015;13(11):1989-1998.

32. Lentz SR, Ehrenforth S, Karim FA, et al. Recombinant factor VIIa analog in the management of hemophilia with inhibitors: results from a multicenter, randomized, controlled trial of vatreptacog alfa. J Thromb Haemost. 2014;12(8):1244-1253. 